\title{
EL AUTOR Y SU SOMBRA. A PROPÓSITO DE LAS LECCIONES DE TERSITES ${ }^{1}$
}

\section{The author and his shadow. On the work The Thersites's Lessons}

\section{Raimundo Cuesta* y Gustavo Hernández Sánchez\&}

Resumen. Este trabajo se despliega en una triple dirección: un ensayo en el que Raimundo Cuesta narra su autobiografía intelectual tomando como motivo su último libro; a continuación, una entrevista que le hace el joven historiador Gustavo Hernández Sánchez; y este último, en tercer lugar, escribe una reseña, incluida a continuación en la sección correspondiente de la revista, que glosa su experiencia y relación personal e intelectual con el autor de las Lecciones de Tersites. En el conjunto de las tres partes se unen las reflexiones historiográficas con los testimonios en clave autobiográfica.

Palabras clave: Autobiografía; Historia de la escuela: Educación; Didáctica crítica; Historia reciente de España.

Abstract. By combining historiographical reflection with an autobiographical narrative, this piece of research is made up of three separate parts. First, an essay by Raimundo Cuesta, where he explains his intellectual autobiography as applied to his last book, Thersites's Lessons. Secondly, an interview with Raimundo Cuesta, conducted by the young historian Gustavo Hernández. Sánchez. And lastly, Hernández Sánchez's review and synthesis of Cuesta's recent book, which is then included in the corresponding section of the journal, as a pretext for describing his personal and intellectual relationship with the author.

Keywords: Autobiography; Schooling History; Education; Critical Teaching Approach; Spain's Contemporary History.

\footnotetext{
${ }^{1}$ Raimundo Cuesta, Las lecciones de Tersites. Semblanza de una vida y una época, 1951-2016 (Madrid: Vision Libros, 2017). Su autor es doctor en Historia, investigador y catedrático jubilado de Educación Secundaria. Gustavo Hernández Sánchez es doctor en Historia por la Universidad de Salamanca, en la que hasta 2017 ha desempeñado docencia en su condición de profesor-investigador en la Facultad de Geografía e Historia.

"Fedicaria-Salamanca. C. Cruz de Caravaca, 2-escal.3-3. ${ }^{\circ}$ B, 37003 Salamanca. España. raicuesta2@ gmail.com

\& Instituto de Estudios Medievales y Renacentistas. Universidad de Salamanca. Casa Dorado Montero. Paseo Rector Esperabé, n. ${ }^{\circ}$ 47. 37008 Salamanca. España. gustavohistoria@usal.es
}

Cómo citar este artículo: Cuesta, Raimundo y Gustavo Hernández Sánchez. «El autor y su sombra. A propósito de Las lecciones de Tersites». Historia y Memoria de la Educación 7 (2018): 683-707. 


\section{UN ENSAYO DE AUTOINTERPRETACIÓN. LA EXPERIENCIA Y LA MEMORIA COMO FUENTE DE CONOCIMIENTO HISTÓRICO. TERSITES SE EXPLICA}

«Uno por uno acaban siendo dos. Yo y mí están constantemente dialogando con apasionamiento» (Nietzsche, Así habló Zaratustra)

\section{GENEALOGÍA DE UN LIBRO Y UN AFÁN HISTORIOGRÁFICO}

La narración de la experiencia personal a través del uso de la memoria de uno mismo hace brotar un formidable manantial de conocimiento sobre la realidad social y su cambiante devenir. Los giros historiográficos de las últimas cuatro décadas lo confirman. Su consiguiente plasmación en el oficio de historiador ha contribuido a erosionar el canon objetivista y el molde explicativo estructural sobre el que sustentaba en Occidente la norma académica posterior a la Segunda Guerra Mundial. No obstante, a pesar de que, una y otra vez, cual cansino ritornello, se anuncia la muerte del sujeto, este no deja de resucitar. Michel Foucault inventó aquello de «función-autor» en su famoso artículo de 1969 (¿Qué es un autor?), en el que, siguiendo las pautas marcadas por la deriva estructuralista de la lingüística y las humanidades, los seres humanos comparecen en la escena social como meros ecos parlantes de una gramática que les precede $\mathrm{y}$, en cierto modo, les constriñe a decir lo que puede ser dicho conforme a reglas preestablecidas. El propio pensador francés debió pensar en él mismo cuando matizó su juicio afirmando que, no obstante todo lo anterior, existían "creadores de discursividad», esto es, individuos capaces de ocasionar alteraciones en el orden discursivo establecido. Claro.

La concepción del lenguaje como entidad al margen de la actividad humana transita por las entretelas de esa proclividad a degradar al sujeto a la paupérrima condición de altavoz de estrictos códigos cifrados y ajenos a la práctica social. Ya tempranamente Raymond Williams (Marxismo y literatura) advirtió sobre los peligros de convertir la lengua en una realidad desconectada de la vida colectiva. En esa misma estela, que tanto ha influido en mí mismo desde mi juventud y hoy en mi faceta de autor de las Lecciones de Tersites, me complace destacar la revolución copernicana que significó en su momento la obra del historiador Edward 
P. Thompson (La formación de la clase obrera en Inglaterra) al defender la importancia decisiva de la experiencia y la práctica de los individuos y de los grupos a la hora de construir las clases, siendo así que la conciencia o identidad de pertenecer a un grupo social no representa un simple reflejo de realidades económicas objetivas sino que es el fruto de un complejo haz de prácticas humanas y de representaciones mentales individuales y colectivas. De ello y de las tradiciones de pensamiento más abiertas y menos deterministas se infiere que resulta plausible contemplar cualquier fenómeno social como espacio de verificación de relaciones intersubjetivas, y, por ello mismo, esta insoslayable dimensión subjetiva se erige en mediación esencial y consustancial de los mejores intentos de explicar el mundo por parte de las más sólidas y solventes teorías sociales.

Pero a la consideración del lenguaje como un hecho social y de la experiencia subjetiva como mediación inevitable, es preciso también añadir la memoria (individual-colectiva) como ingrediente muy recomendable dentro del horizonte de un pensamiento crítico capaz de afrontar la impugnación de la racionalidad tecnocrática de la modernidad. En mi libro, al menos como pretensión, se plasma un ensayo que persigue describir y desmenuzar la experiencia subjetiva y la memoria de alguien que ha vivido entre 1951 y 2016, principalmente entre Santander y Salamanca, valiéndome para ello de diversos procedimientos narrativos.

Ahora bien, Las lecciones de Tersites es para mí mismo una sorprendente criatura intelectual. Existe un texto titulado Borges y yo en el que el autor argentino afirma: "No sé cuál de los dos escribe esta página». Ciertamente, ese extrañamiento y desdoblamiento entre el escritor y sus escritos es consustancial a la dedicación literaria, pero lo nuevo de este caso estriba en que el texto rompe bruscamente con los moldes temáticos y metodológicos de mis obras anteriores. Es más, podría considerarse este libro como una consecuencia no prevista de los diez últimos años que dediqué al estudio del tema de la subjetividad en la modernidad y en la postmodernidad, apoyándome en un amplio abanico de lecturas filosóficas, históricas y literarias. Una brizna de ese quehacer mío se dio a la luz con motivo de la reseña que escribí sobre la biografía de Ortega y Gasset, debida a la pluma de Jordi Gracia, que apareció en 2015 en el segundo número de Historia y Memoria de la Educación. Fuera de tal materialización, todo ese afán no fructificó más que en una recopilación de 
textos y reflexiones parciales sobre la evanescencia del conocimiento del yo, porque, al decir de Fernando Pessoa, «conocerse es errar, y el oráculo que dijo "conócete" propuso un trabajo mayor que el de Hércules y un enigma más negro que el de la Esfinge. Desconocerse conscientemente: he aquí el enigma». De todas aquellas lecturas y meditaciones saqué como enseñanza más ilustrativa que la única manera de asir o dar cauce al yo es la narración.

Ciertamente, el yo, inasible y volátil, existe solo mientras se narra, se piensa y se recuerda la experiencia del existir en el mundo social, porque, en el mismo ejercicio de la escritura, sucede algo parecido a lo que Paul Ricoeur calificaba de «identidad narrativa». Inopinadamente en un momento dado, decidí, a través del artilugio de Tersites, heterónimo literario que resume el hilo conductor de mi propia «leyenda», narrarme, recordarme y juzgar el mundo en el que ha transcurrido mi vida. En suma me convertí a mí mismo en objeto de conocimiento, cuya posibilidad cognoscitiva solo podía alcanzar merced a una calculada distancia gracias al empleo de efectos retóricos de exposición/ocultación del autor en la trama del relato, y acudiendo simultáneamente a una mirada histórica que ponía al sujeto ante las circunstancia históricas de su tiempo a fin de comprender y explicar mejor el mundo generacional, social y profesional en el que ha acontecido la vida de Tersites entre 1951 y 2016. La existencia envolvente de ese trasfondo histórico evita que el autoanálisis del yo se convierta en un trivial espectáculo narcisista a la búsqueda del escándalo y la notoriedad, tal como es moneda corriente en la sociedad-medu$s a$, traslúcida y tóxica, de la era del totalcapitalismo.

\section{LA IDENTIDAD NARRATIVA DE TERSITES}

Como es sabido, Tersites es un personaje de la Ilíada, libro de innumerables lecturas y frecuente compañero de mis ocios más placenteros. Los partidarios de la teoría de la recepción sostienen que la obra literaria es no solo una creación del autor, sino también un producto de la reelaboración efectuada por cada uno de sus lectores o lectoras. Sin duda, cualquier texto es un río fluyente y cada vez que nos sumergimos en sus aguas estas no son las mismas y nosotros tampoco. Esta faceta, que autoriza múltiples interpretaciones del texto, a modo de una hermenéutica infinita, se hace muy patente en el poema épico atribuido a Homero. 
Normalmente, en las exégesis tradicionales, nacidas de la lectura directa de las palabras del aedo ciego, Tersites era un pobre charlatán, majadero, protestón, feo e insolente, que se enfrenta en la asamblea a los poderosos príncipes aqueos. Frente a esta interpretación, mi Tersites encarna el coraje de decir la verdad (el desastre absurdo de la guerra de Troya), de enfrentarse a sus caudillos militares y, en última instancia, de practicar la virtud de la rebeldía. De ahí que mi obra rinda un homenaje a ese personaje que trasmuto en heterónimo y leyenda de mí mismo; y también, qué duda cabe, representa un explícito reconocimiento a uno de los libros de mi mayor querencia.

En mi Tersites se practica una cierta hibridación de géneros, de modo y manera que es posible una lectura en clave autobiográfica, pero también simultáneamente es factible navegar por el libro como si fuera una travesía histórica por la España del franquismo, la transición y el régimen político actual; incluso lo autobiográfico y lo histórico, nervios medulares del texto, se complementan con partes muy cercanas al ensayo de ideas y otras porciones en las que preferentemente se cultiva una dimensión más estética y directamente afectiva. Por lo demás, siempre concebí la veta literaria, el cultivo del estilo, como un arma intelectual preñada de interés crítico, vigorosa y no meramente ornamental. De ahí que la reflexión sobre la escritura de uno mismo me parezca un formidable principio metodológico de pensamiento. Cultivé, pues, esa voluntad de estilo desdeñosa con los atajos expresivos que contribuyen a trivializar, estandarizar y desdibujar el necesario rigor de todo conocimiento del mundo.

En fin, los escritos que contiene mi libro son de temática muy diversa ahormados dentro de géneros literarios diferentes y un tanto superpuestos (relato, autobiografía, poética, ensayo, etc.), que se organizan en tres partes. Las dos primeras poseen una mayor intención autobiográfica y, aunque en la inicial habla Tersites, sombra de mí mismo, en la segunda en cambio, yo tomo las riendas del relato, de manera que la argamasa que une a ambas porciones aparece como una trama narrativa de sucesión cronológica. En las dos, parafraseando los famosísimos ensayos de Michel Montaigne, "yo mismo soy la materia de mi libro». Tanto en La forja de un tal Tersites (I) como en Tersites repasa sus lecciones. Desmemorias de un profesor (II), a pesar de utilizar respectivamente estilos en tercera y en primera persona, se pretende exponer, entre otros aspectos, un friso de la 
experiencia del autor como alumno (colegios privados confesionales, instituto y universidad) y luego como profesor (en el IES Fray Luis de León de Salamanca). En cierto modo, me pregunto a lo largo del discurrir de mi texto sobre las insuficiencias estructurales de la institución escolar de la que abominé desde la niñez y sobre la que trato de ofrecer los recuerdos más vivos que han alimentado ese permanente desasosiego en torno a esos espacios de socialización forzosa. Deudor de la tradición interpretativa que considera las instituciones totales como aparatos de control social de cuerpos y almas, sin embargo juzgo mi dilatada y satisfactoria labor de profesor como una cierta venganza retrospectiva respecto a mis vivencias como escolar. Precisamente mis formulaciones sobre la didáctica crítica y mi vida profesional aparecen como un intento de encontrar, dentro de la actual escuela estatal, espacios públicos en los que experimentar formas de pensar y actuar de carácter contrahegemónico. Creo que he descrito mi carrera profesional, desde la fundación de grupos de renovación pedagógica hasta la agudización de la mirada crítica que desembocó en mi Felices y escolarizados. En ese camino se encuentran las fuentes donde he bebido (Marx, Weber, Benjamin, Escuela de Fráncfort, Foucault, Bourdieu, Thompson, Lerena, etc.) y el eco que tales nutrientes ha tenido en mi tarea como historiador de las disciplinas escolares, de la institución escolar y como promotor, dentro y fuera de Fedicaria, de una cierta consideración teórico-práctica de la didáctica de la historia. Por otra parte, las abundantes citas en las que reconozco mis deudas intelectuales no intentan ser un tedioso ejercicio de escoliasta citatorio al uso academicista, sino una vía de autoanálisis y de genealogía de cómo he llegado a amasar mi propio pensamiento, que es de mi propiedad solo en sentido figurado, porque la actividad intelectual personal es siempre la consecuencia de un destilado de ideas adquiridas en un alambique de socialización y apropiación subjetiva, a veces poco o nada consciente, de las ideas ajenas.

Los dos primeros libros, pues, dibujan la trayectoria en el seno de instituciones formales de educación en el contexto de mi interpretación sobre las grandes líneas culturales y políticas del mundo y de España. Por el contrario, Periferias y otras subjetividades (III) es de muy distinta naturaleza. Se compone de una suerte de destellos literarios, de unos $p a-$ ralipomena (una suerte de compilación de lo omitido en otros escritos), que quiere complementar el retrato autobiográfico ofrecido en los dos 
libros anteriores. En él figuran narraciones de viajes, poemas de amor y cartas elegíacas.

\section{UN RETRATO CUBISTA SOBRE EL BASTIDOR DE LA HISTORIA RECIENTE DE ESPAÑA}

En 1986 ya advertía Pierre Bourdieu contra «la ilusión biográfica» y en esas anduvo hasta el final de sus días retomando en su Autoanálisis de un sociólogo, o sea de él mismo, el pesimismo sobre la imposible empresa de narrar al sujeto. Los historiadores, tradicionalmente más partidarios de practicar la «apuesta biográfica», dirían que esos achaques de sociólogo son infundados. Claro que nadie osaría hoy practicar la biografía heroica al estilo decimonónico, por ejemplo al modo de un Thomas Carlyle, pero, por encima de gremios de los que siempre escapé como de la peste, yo preferiría hablar de la paradoja autobiográfica. Parafraseando la lúcida obra de Jesús Ibáñez (El regreso del sujeto), reclamo la dimensión aporética de todo pensamiento crítico y me gustaría afirmar, al lado del preclaro sociólogo cántabro, que la investigación social es una tarea necesaria y a la vez imposible en la medida que el sujeto siempre emplea categorías conceptuales, lenguajes y métodos empíricos socialmente mediados.

Sin ignorar estas cautelas y plenamente consciente de la dimensión extremadamente paradójica del acto de escribir sobre uno mismo, en Las lecciones de Tersites me he movido entre dos polos: el carácter representativo de una vida tal como se concibe por la historia social y la biografía "hermenéutica» hija de la deriva postsocial y del papel central del lenguaje. Al final quise dibujar un retrato cubista, complejo, poliédrico, inseguro, etc., como el óleo que ilustra la portada que huye del "realismo», pero profundamente inserto en un fondo histórico.

Es más, se podría afirmar sin ningún rubor que Las lecciones de Tersites contienen una tesis anunciada en las dos citas preliminares. Ambas formalmente figuran en el pórtico del libro, pero, en realidad, subyacen a lo largo del continuo metanarrativo que impregna toda la obra. Una procede de un proverbio árabe, que Marc Bloch menciona en su Introducción a la historia, y que dice: «Los hombres se parecen más a su tiempo que a sus padres». Sabia sentencia que a menudo se ignora y que enmarca mi trabajo en la senda de la historia social al considerar a Tersites y 
sus metamorfosis como un sujeto representativo de una época, un medio social y un espectro generacional. Este aforismo no es, por su puesto, una especie de idea preconcebida o hipótesis de arranque, sino algo que se va construyendo e imponiendo conforme se despliega el curso de la narración, porque la teoría no comparece como un pegamento de un relato que procura tener vida propia. Viene a cuento traer aquí a colación que, al terminar de publicar mi libro, leí El monarca de las sombras, de Javier Cercas, novela de éxito que venía envuelta en una faja con una frase que se desliza en un momento del relato: «Ninguna familia escapa a su esencia». Esta afirmación contradice punto por punto lo que yo he perseguido demostrar en Las lecciones de Tersites. Siempre hubiera sido más novelesco suponer un destino aciago que comprender el prosaico mundo de todas las constricciones sociales que nos han forjado con o contra (o ambas cosas a la vez) nuestros padres. Desde luego, la metamorfosis de la conciencia política de los hijos de los vencedores de la Guerra Civil, uno de los temas centrales de mi obra, constituye un fenómeno social trascendental, que no se debe ni a oscuras fuerzas telúricas ni a ineluctables determinantes genéticos.

La segunda cita-pórtico corresponde a Raymond Williams (Es usted marxista, ¿verdad?). Si bien se mira, las alusiones de este tipo se ponen una vez terminada la obra, aunque casi siempre figuran artificiosamente como consideración previa, cuando, en verdad, son reflexiones-síntesis posteriores a la creación literaria. El pensador británico, uno de los grandes promotores del giro cultural en los estudios sociales, dice: «Si hacemos el esfuerzo necesario, a lo largo de nuestra vida descubrimos en lo más profundo de nosotros mismos [...] las estructuras de sentimiento de una determinada sociedad». Esta consideración resulta convergente y complementaria del proverbio árabe y nos remite a la idea de cómo se procesan y organizan en la experiencia individual las representaciones colectivas que empapan la vida afectiva.

En definitiva, conviene subrayar más la relevancia del giro hacia el sujeto que ha envuelto la historiografía de las últimas décadas y que, por supuesto, también ha llegado a la historia de la educación. La cantidad de biografías, memorias y testimonios de docentes, estudiantes, administradores, etc., compone hoy una rica panoplia que acredita también ese positivo retorno de la experiencia y de la memoria al terreno de la 
investigación educativa. No son pocas, sin embargo, las cautelas que hay que adoptar al internarse en la selva de los testimonios de la subjetividad de los agentes educativos. En mis trabajos de la última década he defendido la práctica de una historia con memoria, esto es, una historia que sin omitir lar armas del oficio de historiador permanezca atenta a las pulsiones y esperanzas de ese "pasado ausente», lo que requiere romper amarras con el positivismo ramplón y con la vana tendencia historicista de entender el flujo de la historia humana como un camino de perfección hacia la conquista de los valores y realidades imperantes en el mundo capitalista de Occidente. En fin, Tersites no pretende dar lecciones a nadie porque entiende que, en el curso de la vida, de los trabajos y de los días, las lecciones tanto se dan como se reciben.

\section{RAIMUNDO CUESTA ENTREVISTADO POR GUSTAVO HERNÁNDEZ}

- Raimundo, enhorabuena por tu libro. Si te parece, nos metemos directamente en materia. Afirma el pensador coreano asentado en Alemania, Byung Chul Han, en su obra $\mathrm{El}$ aroma del tiempo (2015), que la verdad es un fenómeno temporal, también la experiencia. Tú entiendes la experiencia social como mediación generadora de conocimiento, y así lo reflejas en la obra. ¿En qué sentido ha influido esta relación entre el tiempo y la experiencia en tu relato? ¿Se podría decir que es la columna vertebral/articulación del mismo? ¿Qué tiene de experiencia (experiencia de vida) y qué tiene de información (fuente histórica) tu relato?

Todo lo humano es social y, por lo tanto, temporal. La pretensión de veracidad de un discurso es una dimensión que tampoco escapa a ese "aroma del tiempo», que todo lo empapa, que todo lo sumerge en un curso fluyente y como inaprensible. En mi libro he dibujado una semblanza biográfica de mi existencia social, que irremediablemente se alimenta de una memoria de experiencias biográficas sucesivas hilvanadas cronológicamente. Parafraseando a Martin Heidegger, un autor de tu gusto, somos arrojados a la vida para la muerte en un itinerario vital dentro del que el lenguaje nos permite hacer de espejo de nosotros mismos y comunicarnos con los demás. En mi opinión, el individuo cobra sentido a través de un flujo de experiencias vitales resultantes de la interacción con los demás, de modo y manera que las experiencias intersubjetivas son la mediación imprescindible que nos permite comprender tanto al individuo, 
que encarna una determinada materialización de las relaciones sociales, como a la colectividad. Tal experiencia del sujeto, como sugieres, es siempre temporal y, desde luego, cuando se explicita por escrito se constituye al mismo tiempo en testimonio vivo y en fuente valiosa para el conocimiento histórico. Ese deseo de probar con el conocimiento histórico de mí mismo representa, en gran medida, el resorte que me movió a escribir Las lecciones de Tersites.

- Como historiadores, después de hablar del tiempo, sería preciso hacer una referencia al espacio. Una cuestión que me llamó mucho la atención a partir de la lectura de tu libro es la experiencia del espacio, de los paisajes y de los lugares de una vida. En esos pasajes se revela tu condición de geógrafo, no solo de historiador. En cambio, la descripción que vas trazando de los distintos personajes es menos concreta, mucho más accesoria, podríamos decir que cobra un talante de metáfora en tanto que se caricaturiza o deforma cobrando un sentido más literario que descriptivo. ¿Acaso haces una distinción entre la realidad material, el entorno, la geografía, y la subjetivización de la misma en los individuos (experiencia de los otros)? ¿Cómo podrías explicar estas dicotomías?

Citabas antes, Gustavo, el «aroma del tiempo» del filósofo coreano-alemán, pero también podría hablarse de un "aroma del espacio». Nuestra experiencia vital está atravesada por esos aromas, que, como en la célebre novela de Proust, son auténticos disparadores de la memoria. Los clásicos tratados sobre la memoria artificial (la mnemotécnica) acudían a los loci para fijar el discurso del orador, asociándolo a espacios imaginarios (habitaciones de una casa, partes de un teatro, etc.). Más allá de estos artilugios trasnochados, el espacio para el sujeto es un espacio vivido y percibido de acuerdo con la historia de cada cual. Desde hace mucho tiempo la geografía más interesante ha dejado de contemplar el paisaje solo como una realidad fósil, de modo que, por ejemplo, la geografía de la percepción hace intervenir la disposición cognitiva del sujeto y sus sentimientos a la hora de enfrentarse a los lugares de su medio. Cada persona posee, como también pone de relieve la psicología, mapas mentales que el individuo "pone» al relacionarse con su entorno. Estos mapas son también síntesis afectivas que nos enfrentan de manera subjetiva con la realidad geográfica. Topofilia y topofobia muestran dos caras de la moneda de nuestras vivencias espaciales. En mi libro hay frecuen- 
tes descripciones de los lugares principales en los que he vivido (Cantabria y Salamanca), pero no solo comparece esa emoción del paisaje en los textos narrativos, sino también en los de carga más expresamente poética, que se recogen en la última parte del texto.

Por lo demás, no comparto tu opinión acerca de que mi narración incurra en una dicotomía persistente o voluntaria, entre el dibujo de personajes y el de paisajes. Al menos esa no era mi intención. Sí es cierto que a veces cargo la mano a la hora de describir alguno de mis profesores y otros seres humanos a los que profeso una indestructible antipatía. En ello hay, sin duda, una carga más subjetiva y caricaturesca, pero personas y paisajes son realidades materiales en tanto que objetos de conocimiento que solo podemos comprender y «exponer» mediante el lenguaje. La dimensión metafórica, como insiste una rama de la historiografía conceptual, es inherente al conocimiento de lo social.

- Estoy de acuerdo contigo, Raimundo. Las cuestiones que comentas son interesantes y darían para hablar mucho rato, pero debemos acotar la entrevista para no extendernos demasiado. En el libro, tu experiencia educativa es tratada como objeto histórico. Sin duda, constituye una fuente histórica para la historia de la educación, tal y como antes afirmabas, campo en el que te has convertido en todo un clásico. En este relato que presentas, fruto de un desdoblamiento de tu yo (Raimundo como Tersites) la experiencia escolar es otra cuestión central. ¿Forma parte del sentido de la conformación de un sujeto-Raimundo-profesor? ¿Hasta qué punto es real -entiendo que sí lo es-y hasta qué punto es el sentido que pretendes aportar a tu existencia en esta recapitulación de tu vida?

En la decimonónica querella española sobre la libertad de cátedra, los ultras católicos arremetieron contra la filosofía krausista acusando a sus partidarios de ser «textos vivos» de doctrinas nefandas. Salvando todas las distancias, la expresión es apropiada para entender que los profesores y profesoras somos en nuestra carrera profesional auténticos «textos vivos», cuya experiencia representa hoy una fuente de primer orden, como vienen a reconocer los nuevos planteamientos culturales de la historia de la educación. Las lecciones de Tersites pretenden, entre otras metas, contribuir a generar conocimiento sobre la educación en el franquismo, la transición y la actualidad. 
Efectivamente, en el libro I (La forja de un tal Tersites) narro en tercera persona y valiéndome de un heterónimo, entre otros aspectos decisivos, mi experiencia como alumno desde la escuela primaria hasta la universidad. Con este artificio he buscado una distancia óptima entre sujeto narrador y sujeto narrado, lo que facilita el recurso a efectos literarios que nada tienen que ver con el oficio del historiador. Tersites era un niño que no quería ir a la escuela y que, sin embargo, hizo la primaria con los padres agustinos, buena parte del bachillerato con los hermanos menesianos, el "preuniversitario" en un instituto estatal de bachillerato y la carrera de Filosofía y Letras en la Universidad de Salamanca. Todo este itinerario escolar se verificó durante los años de la dictadura de Franco y las vivencias escolares han dejado una marca bien visible en mi carrera profesional. Como a menudo digo, no sé si con verdad irrefutable, me hice profesor para satisfacer una suerte de venganza retrospectiva, para enderezar muchos de los entuertos que sufrí en mi existencia como escolar.

Posiblemente el poso amargo que dejó en Tersites este ir y venir por las aulas, acentuado sin duda por la ominosa circunstancia de la dictadura franquista, han ejercido algún tipo de influjo no solo en mi dedicación a la docencia, sino también mi obra investigadora sobre la crítica de la historia de la escolarización, por ejemplo, en mi libro Felices y escolarizados, que, de todas formas y en modo alguno, puede colegirse como una mera derivación de una experiencia personal ingrata y dolorosa. En todo caso, tampoco he querido buscar un "significado» retrospectivo de mi vida. Los significados del vivir son inconmensurables y no pueden quedar abarcados en un artefacto literario como es este libro.

- Como señalo de manera más detallada en mi reflexión final, la biografía es un género que retorna dentro de las formas de la narrativa postmoderna. Se trata de una nueva narrativa biográfica distinta de la tradicional, algo que podríamos considerar como un "experimento postmoderno». ¿En qué medida crees que presentas un relato tradicional y en qué medida no? ¿Cómo pueden servir estas nuevas narrativas al historiador a la hora de emplearlas como fuente de información histórica pero también como forma de narración o de conocimiento histórico?

Creo que me muevo entre lo que el historiador francés François Dosse denominaba «biografía modal» (el personaje es «representativo» de la 
vida social) y la «biografía hermenéutica» (el personaje se construye a partir del lenguaje y la interpretación). O sea, mi horizonte combina unas fuertes marcas de historia social (muy presente en todo el libro, desde sus citas de cabecera) con trazos más impresionistas de «historia postsocial», de eso que tú calificas como "experimento postmoderno». Tú, joven historiador, y yo, viejo profesor y cultivador free lance de las artes de Clío, hemos discutido mucho sobre este asunto. En tu reciente libro $\mathrm{La}$ tradición marxista y la encrucijada postmoderna apuestas por una historia social y cultural, que no renuncia a los aportes de la postmodernidad historiográfica. En este terreno creo que hemos ido acercando posiciones.

Lo que tú denominas "experimento postmoderno» no estoy seguro de que se verifique ni «auténticamente» ni sistemáticamente en mi libro. Más bien estimo que aflora de modo esporádico. Se podría decir que el género biográfico o autobiográfico, practicado desde la perspectiva «modal», tiende a devolvernos una imagen del sujeto como una entidad única forjada y sometida a las fuerzas profundas que condicionan el devenir de las personas y de las instituciones. Por el contrario, la «verdad» del sujeto, en clave postmoderna, nos arroja a una visión caleidoscópica, astillada y contradictoria. En mi caso, he querido ensayar esta segunda perspectiva por medio de la superposición, en el curso de todo el relato, de ficción y de no ficción, de literatura e historia. Desde luego, esos fragmentos incontrolables se explayan muy vivamente en los textos poéticos del libro III (Subjetividades y periferias), pero lo más «postmoderno» del libro es que se desvela al lector o lectora que su autor, sin propósito preconcebido, ha elaborado acerca de sí mismo una suerte de "leyenda» unitaria. Así, en resumidas cuentas, se pone en duda la veracidad de que Tersites, más allá de la mirada de su creador, sea algo más que la superposición de experiencias carente del destino manifiesto al que aboca ineluctablemente toda historia autobiográfica. En esa imperiosa necesidad de dar unidad al yo y de proporcionar un argumento diacrónico a la trama narrativa reside parte de lo que Pierre Bourdieu llamara la «ilusión biográfica».

- Si tuviésemos que señalar dos facetas de tu trayectoria profesional e intelectual, la primera sería tu práctica docente a través del concepto de "didáctica crítica de las ciencias sociales", y la segunda, tu dimensión como historiador de la educación, en la que apareces como una figura original 
que desarrolla conceptos propios - hoy ampliamente utilizados por muchas personas - como pueden ser los de código disciplinar o modo de educación. Para ayudar a los más jóvenes como yo o para plantearlo de manera más divulgativa, si tuviésemos que resumirlo: ¿En qué consiste la didáctica crítica de las ciencias sociales? ¿Qué son los códigos disciplinares y qué son los modos de educación?

Mi trayectoria profesional no solo se materializa en escritos que tienen como objeto mi oficio de docente y mi dedicación a la historia de las instituciones educativas dentro de las que he vivido, principalmente los institutos de educación secundaria. Comprendo, naturalmente, que aquí y ahora interesen principalmente, por su repercusión pública, las obras que han forjado un pensamiento de talante crítico. Desde luego, las dos caras principales de mis afanes se pueden resumir en el ejercicio de una crítica de la didáctica y la formulación de una propuesta de didáctica crítica de las ciencias sociales. Como cuento en Las lecciones de Tersites, tras una primera etapa de elaboración de materiales alternativos para la enseñanza de la historia, desde principios de los noventa el énfasis crítico de mi manera de pensar adquiere más intensidad y progresivamente se vincula a un estudio sociogenético del conocimiento escolar.

Precisamente a fin de desentrañar las claves de ese misterio de las materias de enseñanza acuñé, a lo largo de los años noventa, el concepto heurístico de código disciplinar, que ha tenido una acogida considerable entre los historiadores de la educación en España y América Latina. Un concepto heurístico es una herramienta imprescindible para guiar una investigación porque permite construir el objeto de la misma al tiempo que ayuda a desplegar nuevas preguntas y ensayar nuevos métodos. Adelanté y expuse por primera vez tal estratégico hallazgo en una conferencia pronunciada en 1992 en la Universidad de Santiago de Compostela. El código disciplinar es una tradición inventada duradera pero no estática, que se asocia a la racionalidad imperante en la evolución de las instituciones escolares y del conjunto social. Ahí comparece modo de educación, el otro concepto-gemelo con el que pretendí sistematizar las grandes formas modélicas de evolución de las instituciones escolares en la era del capitalismo, distinguiendo dos grandes etapas de desarrollo histórico-educativo en la España contemporánea: el modo de educación tradicional elitista y el modo de educación tecnocrático de masas. 
Código disciplinar y modos de educación nacen estrechamente unidos como las dos grandes palancas con las que aproximarnos a la historia del conocimiento escolar. Otra cosa muy distinta sería comentar cómo se entendieron y difundieron tales conceptos en la comunidad de historiadores o en lugares informales de pensamiento crítico, como Fedicaria.

- ¿Tienes la impresión de que tu obra no ha sido bien comprendida o incluso rechazada dentro de los campos académicos de referencia?

Todo autor está condenado a sufrir un cierto grado de incomprensión, más aún si mete sus sucias pezuñas en un territorio acotado por una comunidad científica impoluta a la que no se pertenece por derecho propio, como es mi caso. Si además se investiga desde plataformas extra-académicas de pensamiento crítico como es Fedicaria, el proyecto Nebraska, etc., evidentemente podemos advertir fricciones y disensos más o menos conscientes. Yo, en mi condición de free lance, he ido a mi aire y se podría decir, que, respecto a comunidades epistemológicas como la de los historiadores de la educación o la de los contemporaneístas, alcancé algún reconocimiento. Por ejemplo, mis aportaciones conceptuales a la historia del curriculum suelen ser de cita obligada en España y en algunos países de América Latina. Pero una cosa es la cita canónica y otra muy distinta el uso y comprensión profunda de ese universo conceptual. Como solía decir Bourdieu, las obras y los conceptos más célebres circulan como un rumor intelectual que impregna los campos académicos, cuyos miembros mencionan a muchos autores ex auditu, o sea, sin haberlos leído. Tampoco cabe ignorar que esta economía política del conocimiento "correcto» obedece tanto a razones no racionales como al inveterado procedimiento mental de captar el mundo mediante esquemas preestablecidos y simplificadores («Raimundo, el del código disciplinar», etc.), que permiten sostener la rotación de ideas y lugares comunes en el seno del campo. Todo esto no me impide subrayar la favorable acogida que mi persona y obra han tenido entre determinados historiadores de la educación. Esta entrevista, creo, es una prueba de ello. De algunos de ellos aprendí mucho.

Afortunadamente nunca precisé acumular capital académico o superar el humillante trámite de las oposiciones para verificar mi labor investigadora. Sin embargo, algunos compañeros de Fedicaria cuando pretendieron el acceso a la docencia universitaria han padecido hostili- 
dades y argucias burrocráticas de todo tipo. Por ejemplo, en el campo de la didáctica de las ciencias sociales las cosas alcanzaron extremos tan indecentes que yo mismo en su día denuncié que ese campo se comportaba más bien como una charca de aguas estancadas.

Otro tema es la investigación y las nuevas generaciones. Me importa, y mucho, subrayar la depauperación de las posiciones críticas dentro del mundo de la investigación más reciente, a pesar del indudable incremento del fondo de trabajos empíricos y la notable multiplicación de tendencias historiográficas. Parece como si una buena parte de los investigadores noveles hubieran renunciado a mostrar intensidad crítica a sus obras, considerando que obras como las nuestras tienen «demasiada» ideología, un exceso de filosofía y una insoportable carga sociologizante. Y así, en la última década, aprecio una suerte de revisionismo de aportaciones como la mía. Me viene ahora a la cabeza el trabajo de un "pretendiente», un joven investigador con aspiraciones, que pasaba revista a los enfoques de la historia de las disciplinas escolares y que dictaminaba que mi supuesto sociologismo era un atentado contra la libertad del profesorado, o sea, que reivindicaba la acción racional y libre de los individuos frente a las instituciones sociales. Este regreso hacia posiciones antisociológicas se presenta como algo creativo cuando no es más que una excrecencia de un neoliberalismo rampante en los círculos del saber establecido en las universidades, invadidas por un capitalismo académico y un individualismo metodológico de notables proclividades anglosajonas. Algunos recientes monográficos de revistas sobre historia del curriculum, o incluso, por poner un ejemplo más cercano, el número 6 (2017) de Historia y Memoria de la Educación, que dedica un lugar especial al tema «Enseñanza de la historia. Análisis de los libros de texto y construcción de identidades colectivas», muestran un patente adelgazamiento del pensamiento crítico. Ese interés por desnudar al conocimiento de su potencial crítico contra el presente también va ocupando posiciones, desde hace bastantes años, en los altavoces oficiales que propagan un mensaje feliz y complaciente sobre la didáctica de las ciencias sociales.

- Pero toda tu labor como historiador, ¿tiene alguna relación con la didáctica crítica? ¿Qué se pude entender por tal?

Relato en Las lecciones de Tersites cómo, primero en Cronos y luego en Fedicaria, se fueron amasando ideas sobre lo que ya en 1999 formu- 
lé, en un artículo publicado en Con-Ciencia Social, nuestra revista, unos postulados de lo que podría entenderse por «didáctica crítica». Para no extenderme en demasía, la idea central, manejada por personas y grupos fedicarianos, consistía en concebir la didáctica de la historia y de otras ciencias sociales como una respuesta a problemas sociales relevantes. Ello implicaba ensayar en las aulas una suerte de lo que luego llamé historia del presente, es decir, un conocimiento histórico atento a los problemas, pero no necesariamente centrado en contenidos del inmediato mundo actual. Esta didáctica yo la entendía como «genealógica», es decir, como capaz de comprender lo que nos pasa hoy a través de un conocimiento histórico de los problemas que nos afectan. Esa idea, más tarde, se vería enriquecida por mis investigaciones sobre el complejo tema de las relaciones entre memoria e historia. Mis últimos años como profesor de instituto, entre 2002 y 2011 , escribí y actué en mi centro tratando de ver el alcance de un uso público del conocimiento histórico a través del programa que titulé Los deberes de la memoria en la educación. Al mismo tiempo fui perfilando el concepto de historia con memoria, que para mí es un ingrediente inevitable de esa didáctica crítica atenta siempre a la experiencia vivida por los que a menudo quedan al margen de la notoriedad histórica, alerta siempre para escuchar lo que W. Benjamin calificó de «pasado ausente», el pasado de los vencidos, de la gente sin historia.

- En Las lecciones de Tersites pareciera como si quisieras establecer una cronología de tu trabajo, ya en tu etapa más madura, y que podríamos resumir en las siguientes etapas: el Raimundo-Tersites militante, que podríamos considerar como la génesis de un pensamiento crítico, alternativo o de carácter contra-hegemónico; el Raimundo-Tersites pedagogo, que aplica esta forma de pensar/práctica pedagógica, traducida en la "didáctica crítica de las ciencias sociales»; y el Raimundo-Tersites pensador crítico, que sería tu etapa actual, en la que reflexionas sobre cuestiones como la historia y la memoria (o una historia con memoria). ¿Me equivoco? ¿Existe un hilo conductor entre los tres Tersites y las dimensiones temáticas de su obra? ¿Hasta qué punto esto es real o se trata solamente de una construcción? ¿No estás siendo demasiado benevolente contigo mismo?

Empezaré por lo último que sugieres como de pasada. De alguna manera, somos esclavos de nuestra autoestima que está reñida con la estima ajena. Si te fijas y recuerdas, en mi libro digo en más de una oca- 
sión que la vida consiste en el aprendizaje de la decepción. En mi caso, la decepción proviene, creo, de una inveterada tendencia a imaginar un «horizonte de expectativas» por encima de su realización en experiencias tangibles. Ese desfase ocasiona melancolía y abatimiento, la sensación de que la decepción respecto a los demás entraña una suerte de fracaso de uno mismo. Mis encontronazos con la realidad nacen de un fondo de deseos siempre incumplidos. No sé si practico una excesiva benevolencia conmigo mismo. Pudiera ser, aunque no soy persona inclinada a convertir su autobiografía en un mero escape para destrozar a los demás o para exponer las inmundicias de uno mismo conforme a la regla imperante en la escandalosa sociedad del espectáculo de nuestro tiempo.

Dicho esto, ciertamente, como adviertes, construyo mi autobiografía intelectual en una secuencia de tres modelos: el Raimundo-Tersites militante, el Raimundo-Tersites pedagogo y el Raimundo-Tersites pensador crítico. Naturalmente esa tríada es una simplificación que ayuda a montar el relato y darle un sentido ex post facto. A poco que se medite, la dimensión crítica puede comparecer y cultivarse o no en cualquiera de las etapas. Pero en esta simplificación hay un notable eco de la verdad que se puede ratificar acudiendo a las fuentes materiales de mi carrera profesional y de mis publicaciones en diversos momentos. Claro que no es pura ficción, posee la categoría de una construcción mental, como lo son todas las representaciones e interpretaciones del mundo.

En realidad, el primer Tersites es un profesor que en 1975, en los estertores del franquismo, empieza su carrera docente como profesor no numerario del Instituto Fray Luis de León de Salamanca y que al mismo tiempo se compromete de manera militante en el antifranquismo. Lo que narro en Las lecciones de Tersites tiene mucho que ver, a manera de biopsia individual del conjunto social, con lo que alguien ha catalogado de efecto de la "generación del 77 », esto es, de aquellas promociones de jóvenes profesores y profesoras que accedieron en torno a ese año y que acabaron cambiando la arcaica faz de esas instituciones docentes una década después. Mi contexto de desarrollo profesional fue el IES Fray Luis de León de Salamanca al que accedí en tiempos en los que Julio Aróstegui era el jefe se seminario de Geografía e Historia, un momento de grandes mutaciones que forjaron las actitudes de muchos de los que fuimos estudiantes antifranquistas. Pasadas las urgencias políticas 
de la transición y cuando ya se hicieron visibles los primeros síntomas del "desencanto», de tal palabra ya se hablaba en 1979, algunos pasamos de la militancia en organizaciones sociales de clase al cultivo de otras preocupaciones más profesionales. Me parece que en el libro explico esta metamorfosis, en los años ochenta, cuando fui cofundador del grupo Cronos. Me dediqué en cuerpo y alma a la elaboración de programas y materiales alternativos para la enseñanza de la Historia, como hicieron otros equipos de renovación pedagógica como Germania, Garbí, etc. Eso es lo que tú Gustavo calificas como «Raimundo-Tersites pedagogo». Desde 1987, coincidiendo con mi etapa de director del Centro de Profesores de Salamanca, cargo al que accedí por votación del profesorado, se combinó en mí una cierta esperanza de hacer algo positivo dentro del marco reformista educativo de los primeros gobiernos del PSOE al tiempo que iniciaba una reflexión más a largo plazo sobre la historia de la enseñanza de la Historia en España.

Esta última dimensión es la que invade mi atención en los años noventa, tras regresar a mi centro en 1990, al tiempo que participo con el grupo Cronos de Salamanca y con Asklepios de Cantabria en la elaboración de una nueva generación de materiales curriculares, que aparecerán publicados con el título de Proyecto Cronos 12-16 para la enseñanza de las Ciencias Sociales. En ese contexto, varios grupos de renovación fundamos Fedicaria en 1995. Los limitados efectos transformadores de lo que, para decirlo de alguna manera, fue la «vía de materiales didácticos», me lleva a profundizar en la investigación de mi tesis doctoral sobre la historia de la enseñanza de la Historia. A partir de ahí lo que tú llamas «Tersites-Raimundo, intelectual crítico» adopta una nueva dimensión, que sin duda también influyó en Fedicaria y en su revista Con-Ciencia Social. En el gozne de entre siglos, mi dotación de lecturas fue creciendo y mis preocupaciones intelectuales se hicieron más incisivas y de más calado teórico. Mi incursión en la historia de las disciplinas escolares me proporcionó un nuevo marco para la explicación de la escolarización y, por ende, para la radicalización de mi pensamiento acerca del significado del capitalismo en su estadio actual. En ese contexto, cobran sentido pleno las investigaciones de toda una década sobre las disciplinas escolares, los modos de educación y los cuerpos docentes, generadas, dentro de Fedicaria, en el seno del proyecto Nebraska, que coordiné hasta 2012 con la colaboración de Julio Mateos y de Juan Mainer. 
¿Hay continuidad en el personaje?, te preguntas. Hay, sin duda, rupturas y continuidades. El pensamiento crítico no es un dogma al que uno se convierte de repente, es cuestión, a menudo, de grados de intensidad. Me reconozco en cada uno de los personajes de cada una de las tres fases. Aprendí cosas distintas y muy importantes en cada una de ellas.

- Me centraré ahora en el papel y uso de la teoría. Un autor sobresale por encima del resto: Bourdieu. Sobre él, parafraseando su obra Las reglas del arte (1995), comentas que la teoría debe ser como el aire que se respira. ¿Qué podrías decir que es lo más interesante del pensamiento de Bourdieu aplicado al estudio de las instituciones escolares?

A menudo tú y yo hemos charlado acerca de lo que supone la teoría en una investigación social y sabes que me place especialmente esa cita en la que se propone usar la teoría como el aire que se respira, como algo que comparece en la investigación de forma natural sin cortes abruptos (aquí la teoría, aquí la parte empírica). Sin embargo, es norma del campo académico, sobre todo en el de las humanidades, separar por un lado, a modo de introducción, el aparato teórico, y por otro lado el cuerpo de datos obtenidos de las fuentes. Habitualmente forman dos cuerpos extraños superpuestos o artificiosamente encajados en un matrimonio postizo. A pesar de todo, el mismo Pierre Bourdieu en algunas de sus obras (desde luego, no en Las reglas del arte) se inclina en exceso por el lado estructuralista. A pesar de todo ello, Bourdieu profesó una sociología sociogenética, atenta a la idea de pensar históricamente.

Esto último es lo que me atrajo siempre del sociólogo francés, cuya obra llena una buena parte de las estanterías de mi biblioteca personal. No obstante, mi relación con la teoría social se verifica de manera pragmática. Parasito las obras de los grandes pensadores siempre y cuando me sirvan para comprender mejor el mundo y pulir las categorías heurísticas de mis indagaciones. Por ejemplo, en mis principales estudios sobre las disciplinas escolares (el código disciplinar de la historia) y los campos profesionales (los catedráticos de instituto) están presentes dos de las categorías centrales bourdieuanas, a saber, campo y habitus. Aunque las llamadas tesis reproduccionistas de la escuela gozan hoy de muy mala fama, leyendo en profundidad la obra del sociólogo francés no creo que pueda derivarse una simplificación mecánica. Es más, su concepto de violencia simbólica, esa coacción no física que obtiene, con el consen- 
timiento de los dominados, legitimación ideológica de las relaciones de dominación existentes, se me antoja muy pertinente para el estudio de la institución escolar.

En el curso de la elaboración de tu tesis, Poder y fuero académico. Las universidades hispánicas. La Salamanca del Barroco (2017), mantuvimos más de una charla sobre Bourdieu. Por aquellos tiempos la editorial Anagrama publicaba en 2014 sus cursos impartidos en el Colegio de Francia Sobre el Estado. Recordarás cómo la concepción del Estado del sociólogo francés benefició a tu trabajo porque permite captar, sin prejuicios liberales, el significado del llamado Estado absoluto de la edad Moderna, caracterizado por un orden jurisdiccional múltiple e intrincado como se muestra en la vida de las universidades del Antiguo Régimen. En fin, la idea relacional del poder autoriza a mirar al Estado anterior al liberal como una entidad mucho más compleja y llena de matices, a mil leguas de la imagen estereotipada proveniente del liberalismo político. Ahí también, ¿recuerdas?, fueron imprescindibles las tesis del historiador Antònio M. Hespanha, con su magnífico y esclarecedor Vísperas de Leviatán, y desde luego también, las aportaciones de Michel Foucault sobre el poder como un fenómeno omnipresente y no basado exclusivamente en relaciones verticales (del Estado hacia abajo), sino en haces de fuerzas multidireccionales.

- Hespanha se atreve incluso a afirmar que hasta el siglo XVIII no deberíamos hablar de Estado (o estructuras estatales) como tal, presentándonos una dinámica del poder en las sociedades de Antiguo Régimen tremendamente compleja y, desde mi punto de vista, más acertada que el paradigma institucionalista tradicional. Pero, vayamos, si te parece a Foucault y su "método genealógico», especialmente cuando hablas de la sociogénesis de las disciplinas escolares y de las raíces de los códigos disciplinares. ¿En qué sentido ha influido el método genealógico de Foucault en tu obra?

Foucault tiene un lugar preeminente como parte de la «caja de herramientas» que, acogiéndome a la célebre expresión de Wittgenstein, es para mí la teoría. También ocupa un lugar preferente en mi biblioteca privada. Por supuesto, en Las lecciones de Tersites solo muy por encima he podido describir el efecto de este autor y otros sobre mi vida intelectual y sobre mi concepción de la escuela. En mi libro a menudo este y 
de otros pensadores son como hilos que hilvanan diversas partes de la narración, que subyacen a ella.

No obstante, con Foucault mantuve un vínculo intelectual un tanto distante, como puede leerse en el monográfico que coordiné para nuestra revista Con-Ciencia Social (2013) a las puertas del trigésimo aniversario de su muerte. Y eso se debe a que la obra de un autor, y más la de un Foucault, no está labrada y confeccionada de una sola pieza. Ninguna obra humana es una totalidad perfectamente coherente. Por ejemplo, entre su historia de la locura y su historia de la sexualidad hay un mar de distancias, aunque existen algunas continuidades. En fin, con este autor he sido muy selectivo. Me interesó y empleé a fondo su veta de impugnador de las instituciones disciplinarias (la escuela entre ellas), pero también he estado atento al viraje subjetivista de sus últimos años, especialmente sobre el cuidado de sí mismo y de los demás.

En cuanto a lo que preguntas sobre el método genealógico, ciertamente me siento deudor de la exégesis que el pensador francés hiciera de la concepción de F. Nietzsche acerca de la genealogía de la moral, que juzgaba los valores dominantes como engaños que velaban su origen miserable. Tal planteamiento lo trasladé a la didáctica crítica concebida como desvelamiento, como descubrimiento histórico de una realidad oculta por los estratos del tiempo.

Precisamente Nietzsche forma parte del trío (los otros dos son Marx y Freud) de los que han sido tildados de «pensadores de la sospecha». Los tres me parecen cemento imprescindible para encofrar un pensamiento crítico de fondo. Ellos serían inspiradores de buena parte de la obra de los teóricos de la llamada Escuela de Fráncfort, que no han dejado de estar presentes en mi trabajo. Desde luego, pensadores como Nietzsche son para mí exponentes de la necesidad de tomar de aquí y de allá y no someterse a una obediencia total de lo tomas o lo dejas. El pensador alemán es un magnífico manantial para el derribo y destrucción de las ideas dominantes tenidas como naturales, pero sus recetas (incluso su propia vida como docente) nada tienen de recomendable. Es esa clase de intelectual, como muy de otra manera hiciera mi admirado Benjamin, extreman la crítica llevándola a un punto de ebullición. Son imprescindibles, pero no suficientes. En fin, Gustavo, mis deudas intelectuales son infinitas y sería 
prolijo hacer más descripción enumerativa; y además muy a menudo he aprendido mucho de los amigos, como ahora charlando contigo.

- Otra pregunta ineludible, a raíz de tus referencias a Raymond Williams: ¿Es usted marxista?

Estoy muy lejos de entender a Marx como un artículo de fe: soy marxista por la gracia de Marx. No me gusta el estilo confesional del pensamiento. Yo prefiero hablar de una larga y complicada tradición marxista, que tú en tanto que animador del Grupo de Estudios Culturales Antonio Gramsci, conoces bien y has reflejado en tu último libro sobre las relaciones entre esa tradición y la encrucijada postmoderna.

Sin duda, la obra de Marx ha sido como un manto envolvente de toda mi primera formación durante la juventud, pero ya en el prólogo que escribí para tu libro expreso las limitaciones aquí y ahora de esa tradición en tres asuntos cardinales: 1) la teoría del valor-trabajo y la explicación del capitalismo actual; 2) el sujeto del cambio social como una clase universal (el proletariado); y 3) la falta de respuesta integral a la problemática medioambiental. En fin, no tengo ningún tipo de obediencia (nunca la tuve) a partido político concreto, pese a ello veo con alguna esperanza la renovación de las izquierdas a partir de los nuevos movimientos sociales. En Las lecciones de Tersites explico cómo, en el caso de España, me fui alejando de aquella democracia a la que quisimos tanto, de ese andamiaje político fruto de la vía española a la democracia, que algunos tildan de «régimen del 78».

- Finalmente, debo aludir a la dimensión literaria-artística de Las lecciones de Tersites, especialmente en el Libro III: Periferias y otras subjetividades. ¿Cuáles habrían sido tus referencias literarias? ¿Cómo valoras este apartado tan difícil de clasificar?

Ciertamente, este es la parte del libro que ha desatado mayor sorpresa y quizás alguna controversia. Se compone de cuatro relatos de viajes (Bogotá, Chile, México y Buenos Aires) y, por añadidura, de un abanico de poemas y de elegías. Uno de los lectores de los primeros borradores del texto me indicó que esa parte podía romper con las dos anteriores, que son, en efecto, de naturaleza muy diferente. Pensé mucho sobre ello, pero al final consideré que esas astillas de experiencia emocional y de profunda intención estética eran parte del sujeto que se analiza y narra 
en el libro. En verdad, son periferias de mi vida. Lo cierto es que Las lecciones de Tersites acabaron siendo el destilado impremeditado de un proyecto más amplio y ambicioso sobre la subjetividad en la era de la postmodernidad, que nunca concluí. No obstante, los cuatro relatos de viajes enlazan con la parte en la que hablo de mi vida profesional, aunque son en cierto modo un ejercicio literario "desinteresado» y una muestra de cómo al describir una ciudad o un país construimos y reconstruimos permanentemente su realidad imaginada.

Por el contrario, los textos poéticos y elegíacos más bien complementarían el dibujo cubista de mí mismo, compuesto de muchos prismas. Uno de ellos, el menos público y conocido, es la dimensión afectiva hacia las personas queridas, que solo encuentra lugar como una parte de la narración de mí mismo. Este tipo de literatura constituye una fuente huidiza y compleja del yo, porque ahí lo afectivo-estético casi esconde todo lo demás. Opté por su publicación a pesar de que en mi libro he evitado la egolatría y el narcisismo obsceno de lo que el ya citado ensayista coreano-alemán denomina sociedad de la transparencia. Por lo tanto, esta parte, más que una impúdica muestra de sentimientos privados, alumbra una permanente voluntad estética que ha marcado porción muy trascendental de mi curso vital. En general y muy especialmente en esta tercera parte del libro vengo a cultivar una suerte de elipsis, una especie de combinada exhibición y ocultamiento del sujeto. Al final, si bien se mira la existencia de Tersites, transcurre en ese intersticio evanescente de luces y sombras, que, de alguna manera, todos experimentamos en nuestras vidas.

\section{Nota sobre los autores}

Raimundo Cuesta Fernández es doctor en Historia por la Universidad de Salamanca. Ha sido catedrático de Historia en el IES Fray Luis de León de esa misma ciudad. Colaborador con universidades españolas e iberoamericanas, es especialista en historia de las disciplinas escolares, historia de la educación, didáctica y las relaciones entre memoria e historia. Ha participado en programas de formación del profesorado, de innovación (Premio Nacional a la Innovación Educativa en 1985) y renovación pedagógica en España (cofundador del grupo Cronos y de Fedicaria). Pertenece al Consejo de Redacción de la revista Con-Ciencia Social. En la 
actualidad investiga la relación entre genealogía, historia conceptual y memoria. En el campo de la historia del currículo destaca su Sociogénesis de una disciplina escolar: la historia, (Barcelona: Pomares, 1997). En Los deberes de la memoria en la educación (Barcelona: Octaedro, 2007) aborda la dimensión formativa de la memoria. Véanse también en 2011 «El lugar de la memoria en la educación», Con-Ciencia Social,15 (2011) y "Genealogía y cambio conceptual. Educación, historia y crítica», Archivos Analíticos de Políticas Educativas, 22 (23), (2014). Disponible en http://dx.doi. org/10.14507/epaa.v22n23.2014. Véase relación de publicaciones más completas en www.nebraskaria.org

Gustavo Hernández Sánchez es Doctor en Historia Moderna por la Universidad de Salamanca. Realizó la tesis con un contrato FPU del Ministerio de Educación, Cultura y Deporte en el Departamento de Historia Medieval, Moderna y Contemporánea de la Universidad de Salamanca. Su tesis versa sobre el fuero universitario en las Universidades Hispánicas durante el siglo XVII, centrado en el caso salmantino, y ha ganado el accésit del V Premio de Jóvenes Historiadores de la Fundación Española de Historia Moderna. Su otra línea de investigación es sobre la teoría de la historia e historiografía, con la que ha publicado su primer ensayo: El marxismo y la encrucijada postmoderna: Notas para una historia social y cultural (Visión Libros, 2017). Miembro del Grupo de Investigación Reconocido (GIR) «Historia Cultural y Universidades, Alfonso IX» del Instituto de Estudios Medievales y Renacentistas de la Universidad de Salamanca (IEMYR) y del Proyecto de Investigación «La corona y las universidades en el mundo hispánico. Siglos XVI-XVIII», proyecto PAPIIT, Instituto de Investigaciones sobre la Universidad y la Educación (IISUE) de la Universidad Nacional Autónoma de México (UNAM). Ha realizado estancias de investigación en la School of Histories, Languages \& Cultures de la Universidad de Liverpool y el Instituto de Investigaciones Históricas de la UNAM. Actualmente es miembro colaborador del Centro de I\&D sobre Direito e Sociedade (CEDIS) de la Facultad de Derecho, Universidad Nova de Lisboa. Miembro cofundador del Grupo de Estudios Culturales Antonio Gramsci. Actualmente no recibe financiación pública. 